\title{
ASISTENCIA PENAL INTERNACIONAL Y EXTRADICIÓN EN LOS DELITOS \\ DE CRIMEN ORGANIZADO \\ TRANSFRONTERIZO: MERCOSUR Y FUENTE NACIONAL URUGUAYA
}

\section{ASSISTÊNCIA PENAL INTERNACIONAL E EXTRADICÃO EM DELITOS DE CRIME ORGANIZADO TRANSFRONTEIRIÇO: MERCOSUL E FONTE NACIONAL URUGUAIA}

Carlos Álvarez Cozzi

Resumen: Se analizan los principales instrumentos de asistencia penal internacional y extradición contra la delincuencia organizada trasnacional aprobados por los Estados del MERCOSUR para enfrentar a un fenómeno global que moviliza cientos de millones de dólares en todo el orbe. Dichos instrumentos, para una lucha más eficaz, prevén nuevas formas especializadas tales como novedosas formas de investigación, la videoconferencia, el agente encubierto, la vigilancia electrónica, las entregas vigiladas, como medios de prueba. Porque a la trasnacionalización de la delincuencia organizada, debe seguir la cooperación interestatal de la comunidad internacional, como única forma de lucha contra el flagelo del crimen organizado transfronterizo.

Resumo: São analisados os principais instrumentos de assistência penal internacional e extradição contra a criminalidade organizada transnacional aprovada pelos Estados do MERCOSUL enfrentar mesmo um fenômeno global que mobiliza centenas de milhões de dólares em todo o mundo. Esses instrumentos, para uma luta mais eficaz, preveem novas formas especializadas, como novas formas de investigação, videoconferência, agente secreto, vigilância eletrônica, entregas supervisionadas, como evidências. Porque à transnacionalização do crime organizado, deve seguir a cooperação interestadual da comunidade internacional como a única maneira de combater o flagelo do crime organizado transfronteiriço.

* Universidad de la República, Uruguay.

E-mail: alvarezcozziabog@gmail.com

Recibido: 16/08/2017. Aceptado: 14/09/2017. 
Palabras clave: Asistencia penal internacional, Crimen Organizado trasnacional, MERCOSUR

Palavras-chave: Assistência Penal Internacional, Crime Organizado Transnacional, MERCOSUL

\section{INTRODUCCIÓN}

La globalización también ha influido acelerando la difusión de los delitos organizados transnacionales. El narcotráfico se ha visto potenciado por el lavado de activos y la financiación del terrorismo internacional. Asimismo, estos delitos se presentan vinculados con la corrupción de algunos funcionarios públicos y gobernantes. A la extensión de estos fenómenos de delitos organizados por verdaderas mafias internacionales debe seguir la coordinación estatal interdependiente de la comunidad organizada para el combate efectivo de estos delitos. Los medios previstos por el derecho internacional penal son la asistencia penal internacional (de trámite, probatoria, cautelar) y la extradición. Desde 1988 con la fundante Convención de Viena de 1988 (Naciones Unidas) sobre Tráfico Ilícito de Estupefacientes y Sustancias Sicotrópicas, pasando por las posteriores Convenciones contra la Corrupción, interamericana de 1996 y de Naciones Unidas de 2003, la de Nassau de 1992 sobre Asistencia Jurídica Mutua en Asuntos Penales, la de Palermo de 2000 sobre Delito Organizado Transnacional, y por otro lado los protocolos y acuerdos regionales del MERCOSUR, los instrumentos internacionales han tomado una relevancia notoria. Por ello se hace necesaria la difusión de las soluciones provistas por los mismos entre los operadores jurídicos como jueces y fiscales. El módulo se propone analizar todas estas cuestiones, estudiando también aspectos prácticos.

\section{ASISTENCIA PENAL INTERNACIONAL GENERAL}

\subsection{Concepto}

La asistencia penal internacional es la entreayuda jurídica consistente en actos procesales que una autoridad judicial o fiscal de un Estado le solicita a otra autoridad del Estado rogado. La misma puede ser solicitada por sede judicial o fiscal cuando el Derecho interno del Estado requirente así lo autoriza. Los sistemas jurídicos que autorizan a los representantes del Ministerio Público a librar pedidos de asistencia son los que organizan su sistema penal bajo la forma acusatoria, en tanto en ellos son los fiscales, como titulares de la acción penal estatal, los que instruyen la investigación delictual. Los titulares de la asistencia son siempre los Estados por medio de sus agentes, como vimos, jueces o fiscales, jamás los particulares. Estos pueden denunciar 
delitos, dar la "notitia criminis" o ser afectados o concernidos por la asistencia pero jamás tener legitimación activa directa en la asistencia.

\subsection{Clases de asistencia}

Los tipos o clases de asistencia son: de trámite, probatoria y cautelar. Las mismas varían en intensidad de afectación del ordenamiento jurídico del Estado rogado. Mientras quelas solicitudes de asistencia de mero trámite o impulso procesal como citaciones, notificaciones o emplazamientos no generan afectación en el Estado rogado por su diligenciamiento, sirviendo al juicio penal que se lleva adelante en el Estado requirente, las de asistencia procesal probatoria como declaración de testigos, entrega de documentos, realización de pericias, etc., tienen más incidencia que las anteriores, pero igualmente interesan más al Estado requirente que lo que afectan al requerido. Pero la demostración de que este tipo de medidas son un grado más intenso de asistencia que las de mero trámite radica en que, por ejemplo, en los artículos 17 y ss. del vigente Protocolo de San Luis de Asistencia Jurídica Mutua en Asuntos Penales entre los Estados parte del MERCOSUR, y 20 y 22 de la Convención Interamericana de Nassau de 1992 sobre Asistencia Mutua en Materia Penal, se distingue entre testimonios en el Estado requerido y los que se piden sean prestados en el Estado requirente. En este segundo caso, la normativa convencional citada preceptivamente establece que el Estado requirente deberá proporcionar los gastos de traslado de la persona que debe declarar en el rogante, así como la persona citada deberá de prestar su consentimiento para el traslado y se le deberá, conforme al artículo 20 del citado Instrumento, otorgar el correspondiente salvoconducto. Se busca que la citación de la persona al Estado requerido no se pueda convertir en una extradición oblicua. En caso en que se solicite el interrogatorio de la persona en el Estado rogado, se deberá acompañar el texto del mismo para que el juez rogado pueda practicarlo.

La asistencia cautelar es el tercer grado que genera mayor incidencia o afectación en el Estado rogado. Puede ocasionar gravamen irreparable porque afecta a personas o bienes, tales por ejemplo como la ocupación y entrega de objetos, incautaciones, bloqueos de cuentas bancarias, etc. Es por esta razón que para este tercer grado de asistencia que las normas convencionales exigen la doble incriminación para poder prestar la asistencia por parte del Estado rogado, mientras que, en los tipos anteriores de asistencia, de trámite y probatoria, tal requisito no es exigido.

\subsection{Titulares de la asistencia}

Los titulares de la asistencia son exclusivamente los Estados, nunca los particulares. Quienes actúan por los Estados, como ya vimos, 
son los jueces en los Estados en que éstos llevan adelante la instrucción o los fiscales, en aquellos países en que está consagrado el proceso acusatorio, conforme a su Derecho interno. No puede el particular, ni siquiera el afectado por la medida, pretender tener legitimación activa directa para la asistencia penal internacional. Puede si presentarse exponiendo su perjuicio. En un importante caso de asistencia de hace algunos años entre los Estados Unidos y el Uruguay ("Mark Poltera") en que había sido estafado un banco norteamericano (La Salle Bank) por dicha persona de nacionalidad suiza, la Justicia de ese país solicitó, vía autoridades centrales, y obtuvo del nuestro primero la medida cautelar de bloqueo de cuenta de dicha persona en un banco "off shore" que operaba en Uruguay (Deutsche Bank) por casi un millón de dólares. Dentro del plazo previsto por el vigente Tratado de Asistencia Jurídica Mutua entre nuestro país y los Estados Unidos de América, llegó luego al Uruguay el pedido fundado de incautación y transferencia de fondos por ser provenientes del delito, a lo cual el Juzgado Letrado de la. Instancia en lo Penal de 9. Turno hizo lugar y ordenó la transferencia de dichos fondos al banco indicado por la autoridad central norteamericana. En dicho proceso, abogados uruguayos invocando un poder del banco perjudicado por el delito, comparecieron ante el Juez rogado solicitando se le hiciera entrega a ellos de dicha suma, lo cual fue denegado por la sede nacional atento a lo que se viene de exponer en cuanto a que los titulares de la acción y por ello los legitimados son las autoridades estatales, nunca los particulares.

\subsection{Caracteres de la asistencia penal internacional}

La asistencia penal internacional tiene caracteres propios que hacen de ella una figura autónoma, totalmente distinguible de la cooperación civil, comercial y de familia. Responde a principios diferentes por ser los únicos titulares de la misma, según se vio, las autoridades públicas de los Estados requirente y requerido. Los particulares o bien serán denunciantes o concernidos o afectados por la asistencia penal internacional pero nunca titulares o agentes de la misma.

Asimismo especial mención tiene la responsabilidad de los Estados en el diligenciamiento de los pedidos de cooperación. Cada Estado será responsable por las medidas que adopte en el cumplimiento de la asistencia. La ley interna regulará la misma y determinará la cuantía de la misma ante la existencia de daños. Ninguno de los Estados parte será responsable por los daños que puedan surgir de los actos de las autoridades del otro Estado parte. De allí que es fundamental que el Estado requerido, antes de ordenar las medidas pedidas en concepto de asistencia por el Estado requirente, tenga en cuenta esta disposición (ver por ejemplo el artículo 31 de la Convención Interamericana de Nassau 
sobre Asistencia Mutua en Materia Penal, de 1992).

También corresponde señalar que las autoridades deben cuidar que las medidas de asistencia no se puedan transformar en extradiciones oblicuas, razón por la cual se prevén las inmunidades, el salvoconducto y otras garantías (artículos 20 y 22 de la citada Convención Interamericana de Nassau y 17 y ss. y 20 del Protocolo de San Luis de Asistencia Jurídica Mutua en Asuntos Penales entre los Estados parte del MERCOSUR).

En materia de doble incriminación es relevante destacar que expresamente no se exige para las medidas de asistencia, como forma de facilitar su solicitud y diligenciamiento. La Convención Interamericana de Nassau así lo establece en su artículo 5. En el caso del Uruguay también lo exige en su normativa de fuente nacional, para los casos de medidas sobre bienes tales como cautelas, inmovilizaciones, confiscaciones o transferencias, registros, levantamiento de secreto bancario, por el numral 3 del artículo 77 de la Ley No 17016 sobre Estupefacientes así como el artículo 34 de la Ley No 17060 sobre Corrupción.

\subsection{Límites a la asistencia penal}

Los textos convencionales existentes, excluyen de la asistencia a ciertas figuras delictivas como son los delitos políticos, militares y tributarios (artículos 8 y 9 de la Convención Interamericana de Nassau y 5 del Protocolo de San Luis de Asistencia Jurídica Mutua en Asuntos Penales entre los Estados parte del MERCOSUR). Resultan ser exclusiones razonables dispuestas por los textos convencionales atento a la especialidad de los mismos. Asimismo el lit. e. del artículo 9 de la Convención de Nassau así como el lit. e. del artículo 5 del Protocolo de San Luis, establecen que los Estados rogados podrán negarse a cooperar cuando el pedido afecte el orden público, la soberanía, la seguridad o los intereses públicos fundamentales del mismo.

\subsection{Forma y contenido de la solicitud de asistencia}

Los requisitos documentales son regulados por el artículo 10 de la Convención Interamericana de Nassau y por el artículo 6 del Protocolo de San Luis de Asistencia Jurídica Mutua en Asuntos Penales del MERCOSUR. Siguen las regulaciones clásicas de los textos convencionales.

\subsection{Vía o vías de cooperación}

La vía de cooperación moderna elegida fue la autoridad central debido a su original celeridad y eficiencia. Ella se encuentra prevista por el numeral 8 del artículo 7 de la Convención sobre Tráfico Ilícito de Estupefacientes de Viena, artículo XVIII de la Convención Interamericana 
contra la Corrupción, artículo 3 del Protocolo de San Luis del MERCOSUR. Asimismo, en la normativa de fuente nacional uruguaya tanto para narcotráfico (Ley 17016), corrupción (Ley 17060), como para lavado de activos (Leyes 17343 y 17835) también se prevé la autoridad central como única vía de cooperación. No obstante, como se entiende que siempre debe estarse a la facilitación de la cooperación, es admisible que el pedido provenga por la vía diplomática, que también es oficial, aunque sea más lenta, para diligenciamiento por parte de la autoridad requerida. Lamentablemente, en los últimos años, en Uruguay, con la actual conducción de la Autoridad Central, se ha producido un enlentecimiento de la cooperación, que de alguna manera desnaturalizó el ideal de su creación en el Derecho Europeo en la década de los años 60 del siglo XX.

\subsection{Ley aplicable a la asistencia}

Es una clásica regulación la que prevé que el Derecho del Estado requirente regule el libramiento del pedido de asistencia así como que la ley procesal interna del Estado requerido sea la que regule el diligenciamiento de la medida. Así lo establecen el artículo 7 de la Convención de Viena sobre Estupefacientes, el artículo 10 de la Convención de Nassau y los artículos 7 y 8 del Protocolo de San Luis del MERCOSUR.

\subsection{Deber de confidencialidad}

Este deber es asimismo fundamental para asegurar el diligenciamiento de los pedidos y su éxito. El clima de confianza entre requirente y requerido se asegura con este deber. El Estado requirente no podrá utilizar la información que le proporcione el Estado requerido para otros fines para el que la solicitó. En casos excepcionales sólo podrá hacerlo con expresa autorización del Estado que le envió la información. Se prevé la limitación al uso de información o pruebas por el artículo 25 de la Convención Interamericana de Nassau, por el artículo 10 del Protocolo de San Luis del MERCOSUR.

\subsection{Deber de informar entre las autoridades centrales sobre el cumplimiento de la medida}

Este es otro de los deberes básicos sobre los que se asienta la asistencia penal. Ello permite a los magistrados del Estado requirente conocer que pasa en el Estado requerido con el diligenciamiento de la medida e incluso pedir para estar presentes en el Estado rogado cuando se cumpla la misma. En los textos antiguos no aparecía su consagración pero en los modernos lo encontramos en los artículos 16 de Nassau y 11 de San Luis respectivamente. 


\subsection{Textos convencionales multilaterales antiguos con pocas disposiciones sobre asistencia penal internacional: los Tratados de Derecho Penal Internacional de Montevideo de 1889 y 1940}

En el artículo 39 del Tratado de 1889 así como en el 38 del Tratado de 1940, se establece que los objetos del delito incautados al delincuente serán remitidos al Estado requirente. Incluso estas disposiciones podrían ser consideradas que ni siquiera son de asistencia al estar la incautación de los objetos estrechamente vinculada con las consecuencias del delito por el que se solicita la misma extradición.

\subsection{Textos convencionales multilaterales modernos reguladores de la asistencia}

\subsubsection{La "Convención de Nassau de 1992 (OEA) de Asistencia Jurídica Mutua en Asuntos Penales" y su Protocolo Facultativo de 1993}

Han sido ratificados por nuestro país. Pensamos que la Convención es un buen texto, en tanto ello le permite tener tratado con los países americanos con soluciones modernas de asistencia. Consagra soluciones clásicas en materia de asistencia tales como en el artículo 5 la no exigencia de la doble incriminación para la prestación de asistencia salvo las medidas refieran a embargos, secuestros, inspecciones e incautaciones, registros domiciliarios y allanamientos. Es decir que el Estado rogado puede no prestar la asistencia citada cuando el delito perseguido en el requirente no lo sea en el suyo. Incluye dentro de su ámbito de aplicación (artículo 7) actos como medidas de trámite, de prueba y cautelares. Excluye por el artículo 8, la asistencia cuando sea en relación a delitos militares así como por otras situaciones previstas por el artículo 9 como delitos tributarios, delitos políticos o conexos, si afecta el orden público, la soberanía, la seguridad o los intereses públicos fundamentales. Prevé la existencia de autoridades centrales para su aplicación en el artículo 3. Entre las medidas incluidas en la asistencia se encuentran también el registro, embargo, secuestro y entrega de objetos (artículos 13 y 14). En los artículos 17 y siguientes se regula la asistencia probatoria testimonial y por el 20 el traslado de detenidos para declarar en el Estado requirente pero con el salvoconducto previsto por el artículo 22. Por el artículo 24 se regula la remisión de antecedentes e informaciones así como la limitación en el uso de la información y pruebas por el artículo 25 en que se dispone que solo con autorización expresa de la Autoridad Central del Estado rogado, el rogante podrá utilizar la información para otros fines. Finalmente, por el artículo 31 se establece que la ley interna de cada Estado regulará la responsabilidad 
por daños que pudieran emerger de los actos de sus autoridades en la ejecución de esta Convención.

\subsubsection{El "Protocolo de San Luis de Asistencia Jurídica Mutua en Asuntos Penales entre los Estados parte del MERCOSUR"}

Fue suscrito el 25 de mayo de 1996 en San Luis, Argentina y aprobado por Decisión del CMC n ${ }^{\circ}$ 02/996. Fue producto de la elaboración de la Comisión Técnica de la Reunión de Ministros de Justicia del MERCOSUR.

Sigue soluciones clásicas dela asistencia, similares a las ya mencionadas previstas en la Convención Interamericana. El artículo 2 limita el alcance de la asistencia a los actos de trámite, probatorios (prueba documental, pericial y testimonial en el Estado rogado y en el Estado rogante) y cautelares como embargo de bienes, entrega de documentos y elementos de prueba, incautación, transferencia de bienes decomisados y otras medidas de naturaleza similar. Se prevé en el artículo 3 la vía autoridad central para el envío y recepción de los pedidos de asistencia. En cuanto a las autoridades que pueden librar pedidos, el artículo 4 es muy claro en cuanto a que solo pueden ser jueces o fiscales, no previéndose autoridades administrativas. En el 94 Encuentro de la Comisión Técnica de la Reunión de Ministros de Justicia del MERCOSUR, que tuvo lugar en Montevideo en septiembre de 2007, la Delegación de Brasil solicitó poder incluir a las autoridades policiales como legitimadas para librar pedidos de asistencia, lo cual fue desestimado por las restantes delegaciones de los Estados miembros del MERCOSUR así como por los Estados asociados en virtud de la claridad de la disposición comentada del Protocolo. La posibilidad de denegación de la asistencia por parte del Estado rogado está prevista por el artículo 5 y refiere a los delitos militares, delitos políticos o conexos, delitos tributarios, orden público u otros intereses esenciales del Estado requerido. En caso de denegar el pedido, está expresamente previsto que el Estado rogado deberá de informar al rogante de las razones en que se funda tal denegatoria, salvo cuando se trata de la no entrega de copias de documentos oficiales no accesibles al público, en cuyo el Estado rogado no tiene por qué expresar los motivos de su negativa. La forma y contenido de la solicitud están regulados por el artículo 6 y en cuanto a la ley aplicable a los pedidos de asistencia el artículo 7 establece que el diligenciamiento de las solicitudes se regirá por la ley del Estado requerido, previéndose también que el Estado requirente pueda pedir formalidades especiales para el diligenciamiento las que podrán no ser observadas por el Estado rogado si éstos fueran incompatibles con su ley interna. La confidencialidad de la información así como la imposibilidad de mantener tal carácter por parte del Estado rogado están previstos por el artículo 10. La información sobre el cumplimiento (fundamental en la economía del Protocolo) está regulada por el artículo 11. Esta es básica 
para que las autoridades del Estado requirente puedan presenciar, con anuencia de la autoridad del Estado rogado, las pruebas a diligenciarse en éste. La limitación para el empleo de la información o prueba obtenida está regulada por el artículo 12, en que salvo consentimiento previo del Estado requerido (solución similar a la Convención Interamericana de Nassau), el Estado requirente sólo podrá emplear la información o la prueba obtenida en la investigación o el procedimiento indicado en la solicitud. En este mismo sentido, el suscrito a título personal fue co-redactor en el año 2006 de un "protocolo informal sobre confidencialidad de la información", a nivel del Grupo de Expertos en Asistencia Penal y Extradición de los Estados miembros de la OEA, publicado en la página web del Grupo.

Los costos de la asistencia, previstos por el artículo 13, serán soportados por el Estado requerido salvo los derivados de pericias, traducciones y transcripciones, los gastos extraordinarios que provengan del empleo de procedimientos especiales y los costos del viaje de las personas referidas por loa artículos 18 y 19 (declaración testimonial en el Estado requirente).

En cuanto a las formas de asistencia previstas por el Capítulo III se encuentran: la notificación (artículo 14); la entrega de documentos (artículo 15), que como ya se vio supra, en caso de copia de documentos oficiales, cuando el Estado rogado niegue la asistencia no estará obligado siquiera a expresar los motivos de la denegatoria; la declaración testimonial en el Estado requerido (artículo 17), para lo cual el requirente deberá enviar el interrogatorio y los datos de la persona a interrogar; la declaración testimonial en el Estado requirente (artículo 18), con consentimiento de la persona involucrada y haciéndose cargo el Estado requirente de los gastos de traslado y estadía; el traslado de personas sujetas a procedimiento penal (artículo 19), el salvoconducto a otorgar en los casos de traslado de personas para prestar declaración (testigos o peritos) con el límite máximo de hasta 10 días después en que la persona ya no sea necesaria en el Estado requirente. Se prevé asimismo como forma de asistencia la localización o identificación de personas (artículo 21). Es frecuente que en pedidos de asistencia probatoria, solicitados a nuestro país por parte de Brasil y de Argentina, por los que se pretende la declaración de personas en el Estado requirente, se olviden estas disposiciones. Ello determina que nuestras sedes judiciales, previo informe de la Autoridad Central uruguaya, exijan a los mismos el cumplimiento de las citadas normas, en tanto que, de lo contrario, podríamos estar frente a extradiciones oblicuas, lo que no es querido por el Protocolo. Reiterada jurisprudencia tanto judicial como administrativa nacionales han confirmado esta posición, agregando que, cuando existan elementos suficientes, el Estado requirente que cite a una persona a declarar en su Estado como imputado, lo que en realidad debe de hacer es solicitar la extradición de la misma y no este 
tipo de medidas de asistencia penal internacional.

En un segundo escalón de intensidad en la asistencia se prevén en el artículo 22 las medidas cautelares sobre bienes que se someterán en la traba a la ley y a la jurisdicción del Estado requerido. Este asimismo resolverá según su ley, cualquier solicitud relativa a la protección de los derechos de terceros sobre los objetos que sean materia de medidas cautelares, lo que también en doctrina se denomina como "derechos del concernido". En este segundo escalón de asistencia también el Protocolo prevé la entrega de documentos (artículo 23), la custodia y disposición de bienes y la autenticación de documentos y certificaciones (artículo 24). Este Protocolo tiene un alcance general para la asistencia penal, es decir, aplicable para todos los delitos salvo como se vio, los excluidos expresamente. Veremos las diferencias existentes con las formas más especializadas de asistencia penal en materia de narcotráfico, lavado de activos y financiación del terrorismo y corrupción, es decir, en la lucha contra el delito organizado trasnacional. Este protocolo prevé también la existencia de las autoridades centrales para la cooperación internacional. Con base en este texto se solicitó por Brasil a nuestro país, que la prestó rápidamente, -y mereció recientes elogios a nuestra Autoridad Central en varios foros internacionales-, asistencia penal en el caso "Cabo Verde", contra el lavado de activos, con medidas de bloqueos cautelares de cuentas bancarias, actualmente en trámite, por lo que no puedo proporcionar más datos.

\subsection{Normas de fuente nacional}

En materia de normas de fuente nacional, en asistencia penal internacional general, aplicables en ausencia de tratado, el vigente Código del Proceso Penal de 1980 prácticamente no contiene ninguna. El nuevo Código del Proceso Penal (Ley No. 19.293), constituyente de un sistema procesal acusatorio, que luego de varias prórrogas, entrará en vigencia el $1^{\circ}$ de noviembre de 2017 , lamentablemente carece de regulación sobre asistencia penal internacional, por lo que doctrinariamente propusimos una solución analógica al respecto ("Nuevo Codigo del Proceso Penal uruguayo y la asistencia penal internacional)

\section{ASISTENCIA PENAL INTERNACIONAL ESPECIALIZADA EN LA LUCHA CONTRA EL DELITO TRASNACIONAL ORGANIZADO}

\subsection{Concepto}

El concepto de asistencia en este caso es el mismo que para la asistencia penal internacional general ya visto, con la particularidad de que se trata en este caso de delitos organizados trasnacionales, solamente 
cometidos por integrantes o colaboradores de organizaciones criminosas internacionales y no por simples particulares. Como veremos, los textos convencionales que la regulan han desarrollado más profundamente los instrumentos de la misma. Es que al delito trasnacional organizado los Estados deben de responder con formas organizadas y modernas de asistencia penal internacional para intentar neutralizar a dichas verdaderas multinacionales del crimen.

\subsection{Clases}

También en este caso las clases, al igual que en la asistencia penal internacional general son: de trámite, probatoria y cautelar. Con la particularidad de un mayor y especial desarrollo en el segundo y tercer escalón de la cooperación, según se verá.

\subsection{Protagonistas y afectados por la asistencia}

Al igual que en la asistencia general, los titulares de la cooperación son los Estados, que actúan mediante los titulares de sus órganos como jueces y fiscales. Nunca los particulares tienen legitimación directa. Podrán si dar la noticia criminis, aportar prueba y ser afectos por las medidas de asistencia, según se vio y presentarse alegando perjuicios.

\subsection{La Convención de Naciones Unidas de 1988 sobre Tráfico Ilícito de Estupefacientes y Sustancias Sicotrópicas, aprobada por Uruguay por Ley 16759 de 7.9.1994, ratificada y en vigencia}

Este tratado, pionero en la lucha contra el delito organizado trasnacional, previó un importante capítulo sobre la asistencia penal internacional. El artículo 5 regula detalladamente el decomiso de productos derivados del delito del tráfico ilícito de estupefacientes y sustancias sicotrópicas. Las formas de asistencia judicial recíproca están reguladas por el artículo 7. Prevé recepción de declaraciones de personas, presentación de documentos, la realización de inspecciones e incautaciones, el examen de objetos y lugares, facilitación de información y elementos de prueba, entrega de documentos, identificar o detectar el producto, los bienes, los instrumentos u otros elementos con fines probatorios, cualquier otra forma de asistencia autorizado por el derecho interno del Estado requerido, declaración de detenidos en un Estado para que su declaración se utilice en otro, la imposibilidad de alegar secreto bancario para negar la asistencia requerida. El artículo 8 prevé la remisión de antecedentes penales y el artículo 9 regula otras formas de cooperación y capacitación: armonía de ordenamientos jurídicos, establecer canales de comunicación entre 
sus organismos y servicios competentes a fin de facilitar el intercambio rápido y seguro de información sobre los delitos de narcotráfico, cooperación en la realización de investigaciones conjuntas (que luego desarrollará el artículo 19 de la Convención de Palermo de 2000 sobre Delito Trasnacional Organizado). Asimismo se pactaron programas específicos de capacitación de los organismos competentes y promover el intercambio de expertos, previendo la existencia de funcionarios de enlace. Como una novedad, el artículo 11 reguló el instituto de la entrega vigilada. El artículo 17 reguló la asistencia en el tráfico ilícito por mar de sustancias sicotrópicas. Se estableció la existencia de autoridades centrales para esta Convención.

\section{5. "La Convención Interamericana contra la Corrupción” de 1996, aprobada por Uruguay por Ley 17008 de 25 de setiembre de 1998, ratificada por nuestro país y en vigencia}

Esta importante Convención elaborada por el sistema interamericano para la lucha contra otro delito trasnacional organizado como es la corrupción, regula la asistencia y cooperación en el artículo XIV y las medidas sobre bienes por el artículo XV, previendo la identificación, el rastreo, la inmovilización, la confiscación y el decomiso de los bienes obtenidos o derivados de la comisión o del producto de dichos bienes. Por el artículo XVI se establece que el Estado requerido en la asistencia no podrá alegar el secreto bancario. De manera que así se asegura el éxito de las investigaciones en materia de lucha contra la corrupción. Se establece por el artículo XVIII la existencia de las autoridades centrales encargadas de la asistencia.

\section{6. "La Convención de NNUU contra la Corrupción”, suscrita en 2003}

Ha sido aprobada en 2006 y ratificada por el Uruguay. Contiene también soluciones avanzadas en materia de asistencia penal en la misma línea de las convenciones anteriores. Así por el artículo 31 se regulan los embargos, incautaciones y decomisos del producto del delito. Por el artículo 32 se prevé la protección de testigos y peritos y por el artículo 33 la de denunciantes. El artículo 36 prevé la existencia de autoridades especializadas para la Convención. En el artículo 40 se prevé que no podrá alegarse por los Estados el secreto bancario para impedir la asistencia, al igual que en la Convención Interamericana. La jurisdicción se regula por el artículo 15 para la persecución de este delito internacional. El artículo 43 prevé las medidas de asistencia penal internacional en la misma línea de las soluciones vistas. 


\subsection{La Convención de Palermo (Naciones Unidas) de 2000 sobre Delito Organizado Trasnacional}

Esta moderna convención prevé un rico capítulo sobre la asistencia penal internacional. Las Naciones Unidas asumieron la cuestión de la prevención del delito como una de sus responsabilidades ya en 1950 a través de la resolución 415 (V) de la Asamblea General. Esta decisión fue reafirmada por resoluciones posteriores, entre las que pueden mencionarse la $731 \mathrm{~F}$ (XXVII) del 18 de diciembre de 1972, $32 / 59$ y 32/60 del 8 de diciembre de 1977, 35/171 del 15 de diciembre de 1980 y 36/21 del 9 de noviembre de 1981 relativas a la promoción y fortalecimiento de la cooperación internacional en esta esfera. En el año 1989, la Resolución de la Asamblea General 44/1971 del 8 de diciembre, invitó al Consejo Económico y Social a solicitar al Comité de Prevención del Delito y Lucha contra la Delincuencia que prestara atención al fomento de la cooperación internacional en la lucha contra la delincuencia organizada. El Octavo Congreso de las NNUU sobre Prevención del Delito y Tratamiento del Delincuente de 1990, prestó especial atención a la cuestión la cooperación internacional en la lucha contra el delito organizado trasnacional. La idea de preparar una Convención de las NNUU contra el crimen organizado trasnacional se planteó formalmente por primera vez en la Conferencia Ministerial Mundial sobre Delincuencia Organizada Transnacional, celebrada en Nápoles, Italia del 21 al 23 de noviembre de 1994.

La Convención define materialmente en los artículos 2 y 8 que se entiende por grupo estructurado, grupo delictivo organizado, delito grave, bienes, producto del delito, embargo preventivo o incautación, decomiso, entrega vigilada, funcionario público.

El blanqueo del producto se regula por el artículo 6, definiéndolo materialmente. Así se definen la conversión o transferencia de bienes, la ocultación o disimulación de la verdadera naturaleza u origen de los bienes, etc. El artículo 8 regula la corrupción en forma material o directa, así como el artículo 23 establece la obstrucción de la justicia. El Capítulo II del instrumento versa sobre las medidas contra el blanqueo de dinero y la corrupción. El decomiso y la incautación están previstas por el artículo 12. La asistencia penal internacional se desarrolla en el artículo 13. Se prevé la localización, el embargo preventivo, la incautación del producto del delito, los bienes, el equipo u otros instrumentos. Por otra parte, el artículo 14 regula la disposición del producto del delito o de los bienes decomisados. La jurisdicción está prevista por el artículo 15, asumiendo los Estados parte la obligación de establecer su jurisdicción con respecto a los delitos trasnacionales organizados. Se prevén los criterios de territorialidad en la comisión del delito y de nacionalidad de los agentes de la conducta delictiva. 
Como forma especial de asistencia se prevé el traslado de condenados (artículo 17). En cuanto a las formas de asistencia se prevé: el deber de cooperar (artículos 1 y 2), las formas para hacerlo (párrafos 3, 4 y 5): recepción de testimonios, documentos, inspecciones, incautaciones, embargos preventivos, examen de objetos y lugares, pericias, entrega de objetos, identificación del producto del delito, traslado de personas para declarar, información bancaria, etc. Los párrafos 10 a 12, 18 y 27 prevén las medidas de cooperación en materia de prueba testimonial, tanto en el Estado requerido como en el requirente. Se prevé la existencia de las autoridades centrales por el párrafo 13. Los requisitos de las solicitudes de asistencia se regulan por los párrafos 14 y 15 . Vinculado con esto se pacta la reserva de la información trasmitida (párrafos 19 y 20), la posibilidad de denegación de la asistencia (párrafos 8, 9, 21 a 23 y 26), fundada en el orden público internacional, soberanía, seguridad u otros intereses fundamentales del Estado requerido. Los gastos se prevén por el párrafo 28. Sigue la solución clásica de que los mismos corren por cuenta del Estado requerido salvo los que supongan erogaciones especiales o cuantiosos. Se prevén otras formas de cooperación, que profundizan la asistencia: a. investigaciones conjuntas, artículo 19, mediante la celebración de acuerdos bilaterales o multilaterales. Este tema está en agenda justamente de la Comisión Técnica de la Reunión de Ministros de Justicia de los Estados del MERCOSUR y asociados aunque limitado al delito de trata de personas; b. remisión de actuaciones penales, artículo 21; establecimiento de antecedentes penales, artículo 2; cooperación en materia de cumplimiento de la ley, artículos 26 y 27; desarrollo económico y asistencia, artículo 30.

Otros elementos novedosos lo constituyen las técnicas especiales de investigación, artículo 20, entrega vigilada, vigilancia electrónica y operaciones encubiertas.

Por los artículos 24 y 25 se regula la protección de testigos, lo que es fundamental para asegurar que éstos se animen a declarar contra las organizaciones criminales trasnacionales que tanto poderío ostentan y sin cuya previsión mucho se dificultaría su concreción. Se prevé por ejemplo la videoconferencia como medio de asegurar el anonimato de los testigos. La capacitación y la asistencia técnica, fundamentales para entrenar a los agentes de la asistencia, están previstas por el artículo 29. Finalmente las medidas de prevención de la delincuencia trasnacional están previstas por el artículo 31.

\subsection{Normativadefuente nacional uruguayaen materia deasistencia contra el narcotráfico, lavado de activos y corrupción}

Varias leyes nacionales, dictadas en los últimos años a consecuencia de la ratificación por el país de las Convenciones antes vistas en materia 
de lucha contra la delincuencia organizada trasnacional, regulan los delitos de narcotráfico, lavado de activos y corrupción así como establecen normas sobre asistencia penal internacional. En ausencia de tratado, dicha normativa resulta aplicable para los casos nacionales.

\subsubsection{Ley 17016 modificatoria del DL 14294 sobre Estupefacientes y sustancias sicotrópicas}

Regula por primera vez en el Derecho nacional la figura del lavado de dinero producto del narcotráfico, artículos 54 y ss. En los artículos 75 y ss. de esta Ley se regula la asistencia penal internacional previéndose la vía autoridad central en el artículo 76. Las medidas comprendidas por el artículo 75 se prevén medidas de mero trámite, prueba y cautelar o de inmovilización, confiscación, decomiso o transferencia de bienes. El artículo 77 regula el cumplimiento de oficio por parte de las autoridades rogadas nacionales de acuerdo a la ley nacional.

Expresamente no se exige la doble incriminación en el diligenciamiento de los pedidos (artículo 77, numeral 2) salvo en las medidas cautelares que puedan causar daño irreparable como embargos, registros, levantamiento de secreto bancario, entrega de objetos y documentos, etc., en que sí se exigirá por el Estado uruguayo que la conducta perseguida sea delito también en su país, para poder prestar asistencia. El artículo 78 prevé expresamente que solo las autoridades nacionales tienen competencia para tomar medidas en instancia de cooperación, quedando las autoridades extranjeras impedidas totalmente de actuar en territorio nacional. Sí podrán estar presentes con autorización de los jueces uruguayos competentes. El artículo 80 regula por la ley interna uruguaya las eventuales responsabilidades por daños que pudieran emerger de la prestación de asistencia y el Estado uruguayo se reserva el derecho de repetir contra los Estados requirentes.

\subsubsection{Ley 17343 de 25 de mayo de 2001 (Lavado de activos)}

Esta ley amplió el elenco de delitos precedentes del lavado de activos que la ley hasta ese momento preveía solamente que fuera el narcotráfico. Se agregaron terrorismo, contrabando superior a US20.000, (de infeliz inclusión en tanto el Estado rogado no está obligado a prestar asistencia en delitos tributarios) tráfico ilícito de armas, explosivos, municiones o material destinado a su producción, tráfico ilícito de órganos, tejidos y medicamentos, tráfico ilícito de personas, extorsión, secuestro, proxenetismo, tráfico ilícito de sustancias nucleares, de obras de arte, animales o materiales tóxicos. No introdujo modificaciones en materia de asistencia penal internacional. 
3.8.3. Ley 17835 (Sistema de Prevención y Control del Lavado de activos y de la Financiación del terrorismo) de 23 de setiembre de 2004

Esta ley amplió fundamentalmente el elenco de sujetos obligados a reportar y dispuso de más instrumentos para el Estado (en especial a la Unidad de Información y Análisis Financiero del BCU) para el control de este tipo de delitos trasnacionales como es el lavado de activos y el financiamiento del terrorismo. En lo atinente a la lucha contra el delito, aplicable a los pedidos de asistencia judicial internacional, se dispone por el 9, que el juez podrá disponer la circulación y la entrega vigilada de dinero en efectivos, metales preciosos u otros instrumentos monetarios, sustancias tóxicas, estupefacientes, precursores, etc. Por el artículo 11 se regulan las mencionadas entregas vigiladas pero no se previó en la ley el agente encubierto.

\subsubsection{Ley 17060 contra la Corrupción, de 23 de diciembre de} 1998

Esta ley fue la consecuencia nacional de la aprobación y ratificación de la Convención Interamericana de 1996.

Se regularon los delitos de corrupción y en lo atinente a las normas de asistencia penal internacional, aplicables con los países no unidos con el Uruguay por texto convencional, se previó en el Cap. VII "Ámbito internacional" el cohecho y soborno internacionales (artículo 29), el blanqueo de dinero (artículo 30), la previsión de la vía autoridad central por el artículo 34, la exigencia de la doble incriminación para prestar asistencia internacional (artículo 36) y la reserva de la información obtenida por el Estado requirente (artículo 36).

3.8.5. Ley 18494 de 5 de julio de junio de 2009. Control y prevención del lavado de activos y del financiamiento del terrorismo

Por esta norma se agregaron sujetos obligados a reportar operaciones sospechosas de lavado de activos (artículo 2), se agregaron delitos precedentes al de lavado de activos (artículo 8), modificando las leyes $14.294,17.016$ y 17.835 . Asimismo se regularon medidas cautelares, decomiso entrega vigilada, vigilancias electrónicas, la figura del colaborador, los agentes encubiertos y protección de víctimas y testigos. 


\section{LA EXTRADICIÓN EN LOS INSTRUMENTOS GENERALES}

\subsection{Concepto y naturaleza jurídica}

Por extradición se entiende toda entrega que un Estado soberano efectúa a otro, previa solicitud de este último, de una persona que se encuentre en el Estado requerido, para que pueda ser juzgada, o que habiendo ya sido declarada culpable dentro del territorio del Estado requirente, se le haga cumplir la pena impuesta ${ }^{1}$.

Opertti ${ }^{2}$ entiende que se debe de ubicar a la extradición dentro del Derecho Internacional General, cuyos protagonistas son los Estados y no los particulares. Agrega que la extradición está desligada de la asistencia penal porque responde a principios diversos. Coincidimos con esta afirmación porque -a diferencia de Cervini ${ }^{3}$ que considera que insistir con la diferenciación de institutos puede derivar en una pérdida de garantías del concernido en la asistencia- creemos que admitir las diferencias entre ambos, no deja a la asistencia sin garantías. Porque si bien los agentes de ella son exclusivamente los Estados, como venimos de ver, en algunos textos convencionales se establece claramente que el Estado requerido es el responsable por los daños que se puedan ocasionar en el cumplimiento de las medidas (por ej. artículo 26 del Tratado de Asistencia Jurídica Mutua en Asuntos Penales entre Uruguay y Estados Unidos de América), sin que pueda excusarse en que las pidió otro Estado.

\subsection{Clases}

Las clases principales de extradición son activa y pasiva, desde la óptica del Estado que pide o que recibe el pedido de extradición. Asimismo se distingue la llamada extradición simplificada o abreviada, en que el reclamado acepta, ante el juez rogado y en presencia de su defensor, su entrega inmediata al Estado reclamante. Se trata naturalmente de una decisión judicial en todos los casos. La extradición en tránsito para algunos autores es un mero acto administrativo y está prevista en los textos convencionales (Por ej. artículo 27 del Acuerdo de Extradición del MERCOSUR).

\subsection{Fuentes}

La doctrina distingue entre las fuentes nacionales y convencionales. Resulta fundamental la existencia de tratados porque hay Estados que

1 GARCÍA BARROSO, Casimiro. El Procedimiento de extradición. sl.: Colex, 1996.

2 OPERTTI en Curso de Cooperación Penal Internacional, 1994.

3 CERVINI, Raúl. Principios de cooperación judicial penal internacional en el protocolo del MERCOSUR. Disponible en: < http://wold.fder.edu.uy/contenido/penal/pdf/2010/cervini-004.pdf> 
no conceden la extradición si no existe tratado. Nuestro país, y otros latinoamericanos, en cambio, aún en ausencia de convención, conforme a lo establecido por el artículo 13 del Código Penal, puede tramitar solicitudes de extradición.

\subsection{Principios generales de la extradición}

a) Preferencia de las normas convencionales sobre las nacionales: Es un principio clásico del Derecho Internacional General. Surge de los textos convencionales y en el caso del Uruguay además de la normativa procesal penal de fuente nacional.

b) Obligación internacional de conceder la extradición cuando se cumplen los requisitos: Es también un principio convencional en la materia.

c) Principio de legalidad: Son objeto de extradición las personas que cometieron delitos con una pena generalmente fijada en dos años como mínimo. El sistema antiguo en cambio y ya abandonado por los Estados, era de la lista de delitos.

d) Principio de jurisdicción internacional: En principio es competente para solicitar la extradición al Estado requerido, el juez del Estado requirente donde se cometió el delito por el que se reclama a la persona que se encuentra en el otro Estado.

\subsection{Tratados Multilaterales y del MERCOSUR sobre Extradición}

Uruguay es parte de tratados multilaterales como lo son los de Montevideo de Derecho Penal Internacional de 1889 y 1940. Contienen soluciones propias de la época y continúan en vigencia con algunos países. A nivel subregional en 1998 se suscribió el Acuerdo de Extradición entre los Estados parte del MERCOSUR y se elaboró otro espejado entre los Estados parte del MERCOSUR y Bolivia y Chile. Ambos han sido aprobados por el Uruguay. El texto del MERCOSUR actualmente es aplicable por nuestro país con Paraguay y Brasil, mientras que aún no se aplica con la República Argentina, con el cual rige el bilateral suscrito en 1996.

Las principales soluciones consagradas en estos textos refieren a la procedencia de la extradición por delitos graves, es decir, con pena probable a recaer que no sea inferior a los dos años, es decir, de penitenciaría. Se prevé la exigencia de la doble incriminación para otorgar la extradición en todos los casos. Se excluyen los delitos políticos y los conexos con la expresa exclusión en los tratados modernos de los 
delitos de sangre, atentados, etc. dentro del concepto de delito político. Asimismo son excluidos los delitos militares. Se regula en ellos el arresto preventivo con fines de extradición, siguiendo las soluciones clásicas.

Nuestro país no ratificó la Convención Interamericana de Extradición de Caracas, 1981.

Asimismo el Uruguay es parte de muchos tratados bilaterales sobre extradición, antiguos del siglo XIX y XX (Gran Bretaña, Italia, Suiza, Francia) y modernos, suscritos varios de los últimos en la década de los noventa, como con España, Argentina y Chile (ver lista completa en "EXTRADICIÓN, Normas Nacionales y Convencionales", 2a. Edición, 1997, del autor de este trabajo, Editorial Universidad).

\subsubsection{Vías}

Los tratados prevén la vía diplomática para el envío y recepción de pedidos de extradición en forma casi exclusiva y excluyente. Sólo en algunos pocos tratados se previó que la Cancillería lo introduzca al sistema judicial patrio, o lo haga egresar de él, hacia el exterior, por intermedio de la Autoridad Central uruguaya (con Argentina y España por ejemplo), lo que no agrega nada y hace enlentecer la cooperación. Máxime el estado actual en que se encuentra la Autoridad Central. Por lo que entendemos que menos se justifica que se sustituya la vía diplomática por la autoridad central en el reciente Tratado de Extradición suscrito entre nuestro país e Italia.

\subsection{Normas nacionales}

A nivel del derecho de fuente nacional, la extradición tiene escasa regulación. Se refieren a ella los artículos 13 y 14 del Código Penal Ordinario, el artículo 9 del Código Penal Militar. El vigente CPP de 1980 no contiene regulación sobre la extradición y sí la contiene el nuevo CPP, aprobado por Ley No. 19.293, prorrogado en su vigencia varias veces, que regirá desde el $1^{\circ}$ de noviembre de 2017 , artículos 329 y ss, que prevé el arresto preventivo y el proceso de extradición aplicables en ausencia de tratados. cuya vigencia está suspendida. En su momento, año 2004, ante la no vigencia del Código y en tanto éste tiene una buena regulación de la extradición pasiva, propusimos el desglose de este capítulo y su aprobación por norma separada a fin de llenar el vacío sobre el tema en nuestra legislación. Actualmente se encuentra trabajando una comisión para la aprobación de un nuevo CPP. Esperamos que en el mismo se mantenga la buena regulación que presentaba el texto que tiene la vigencia suspendida. 


\section{LA EXTRADICIÓN PREVISTA EN LOS INSTRUMENTOS ESPECÍFICOS DELUCHA CONTRA ELDELITOTRASNACIONAL ORGANIZADO}

Constituyen soluciones específicas entre los Estados para asegurar la entrega de personas que han cometido delitos trasnacionales organizados.

\subsection{La Convención de NNUU de 1988 sobre Tráfico Ilícito de Estupefacientes y Sustancias Sicotrópicas}

El artículo 6 de este texto regula la extradición. Se destaca el numeral 3 de este artículo, por el que se establece que si una parte supedita la extradición a la existencia de un tratado y recibe de otra parte un pedido con la cual no tiene tratado de extradición, podrá considerar la Convención de Estupefacientes como base jurídica para otorgar la misma respecto de los delitos a los que se aplica este artículo. El numeral 7 establece la obligación de los Estados en acelerar los procedimientos de extradición, lo que se justifica plenamente en el combate al delito organizado trasnacional.

\subsection{La Convención Interamericana de OEA de 1996 sobre Corrupción}

El artículo XIII regula el instituto. Prevé también (numeral 3) que a falta de tratado bilateral entre los Estados parte se podrá tomar como base jurídica para conceder la extradición la sola pertenencia a esta Convención, lo que está en el mismo sentido que la solución antes examinada de la Convención de NNUU de Estupefacientes de 1988. Asimismo por el numeral 6 se estable que en caso de que un Estado no entregue a nacionales se obliga a encausarlos por la comisión del delito que se le imputa por parte del Estado requirente, lo que busca que en este tipo de delitos organizados trasnacionales, las conductas no queden impunes nunca.

\subsection{La Convención de NNUU contra la Corrupción de 2003}

Contiene la previsión del artículo 44 sobre el instituto en solución similar a la Convención Interamericana. La pertenencia a la Convención será base suficiente entre los Estados parte para solicitar y otorgar extradiciones aunque no tengan entre sí tratado bilateral. 


\subsection{La Convención de Palermo de 2000 sobre Delincuencia Organizada Trasnacional}

Regula la extradición en el artículo 16. El mismo requiere que para que proceda la extradición en el ámbito de la Convención, que se trate de conductas incluidas como delitos en la misma, de participación en un grupo delictivo organizado, blanqueo del producto del delito, corrupción y obstrucción a la justicia, es decir, que el delito implique la participación de un grupo organizado. Se exige que la persona se encuentre en el Estado requerido. Se prevé el requisito de la doble incriminación. En caso que la solicitud de extradición se base en varios delitos graves diferentes y alguno de ellos no se encuentre comprendido en el ámbito del artículo 16, el Estado requerido podrá aplicar lo dispuesto en este último, también con respecto a dichos delitos. Cuando los Estados involucrados no tengan entre sí tratado de extradición, podrán considerar como base para la misma la vigencia entre ellos de esta Convención de Palermo, solución ya vista en anteriores textos y que busca facilitar la entrega en el combate contra el delito trasnacional organizado. Las condiciones de la extradición se regulan en los párrafos 7 a 9. En cuanto a la nacionalidad del extraditado (párrafos 10 a 12) se establece que si el Estado rogado no accede al pedido en base a que se trata el requerido de un nacional suyo, tiene la obligación de juzgarlo. Si el Estado rogado para acceder a la extradición solicitada lo condiciona a que, cuando recaiga sentencia, el mismo sea devuelto al Estado donde se encontraba, la extradición podrá concederse condicionalmente. Asimismo, si se denegase la extradición de un nacional para cumplir la sentencia en otro Estado, aquél podrá hacer cumplir la condena impuesta o el resto pendiente de la misma.

La denegación de la extradición está regulada en los párrafos 14 a 16. Se puede fundar en que el Estado requirente pueda imponer una pena o castigar a una persona por razones de sexo, raza, religión, nacionalidad, origen étnico u opiniones políticas o que su cumplimiento ocasionara perjuicios a la posición de esa persona por cualquiera de estas razones. Se establece que no se podrá denegar una solicitud de extradición por el único motivo de considerar que el delito entraña también cuestiones tributarias. Antes de denegar la extradición, el Estado rogado deberá consultar al Estado requirente para darle oportunidad de presentar sus opiniones y proporcionar información pertinente a su alegato.

\section{CONCLUSIONES}

Se advierte una clara evolución en los instrumentos de asistencia penal internacional entre los textos aplicables en general a todos los delitos de los que aplican a los delitos trasnacionales organizados como 
el narcotráfico, el lavado de activos y financiamiento del terrorismo y la corrupción. Por eso es necesario difundirlos, sobre todo entre los aplicadores del Derecho, para que los utilicen.

Creemos con el magistrado de la Audiencia Nacional de España, Javier Gómez, que la asistencia penal internacional es tan fuerte como el punto más débil de la cadena (jueces-fiscales-autoridades centrales). Y por ello en una reunión de puntos de contacto de IBERRED, hace unos años, nos proponía una estrecha colaboración basada en la confianza mutua entre los operadores del Derecho y las autoridades centrales, por ser ella imprescindible. Esa misma postura es la que venimos observando en todos los foros: mundial, Naciones Unidas contra la Droga y el Delito, en reunión de autoridades centrales en materia penal, Brasilia, noviembre de 2007; continental, en Reunión de Ministros de Justicia y Procuradores Generales de las Américas (REMJA), así como en su Grupo de Expertos en Asistencia Penal Internacional y Extradición; y regional, a nivel de la Comisión Técnica de la Reunión de Ministros de Justicia del MERCOSUR y Estados Asociados.

El elenco de medidas probatorias y cautelares se ha enriquecido notoriamente (incautaciones, entrega de objetos, bloqueo de cuentas, transferencia de fondos, no posibilidad de oponer el secreto bancario, etc.) si observamos en particular la Convención de Palermo y la comparamos con los tratados que regulan la asistencia para los delitos comunes. Esto está impuesto por la urgencia y la necesidad del éxito de los Estados en el combate contra el crimen organizado. Asimismo en lo atinente a la extradición, en las convenciones antes analizadas, se observa un mayor interés en asegurar la entrega de los delincuentes respetando siempre las garantías del debido proceso.

En materia de extradición, a nivel convencional insistimos que debe mantenerse la vía diplomática para el envío y recepción de las demandas extradicionales, como hasta ahora ha sucedido y no cambiarla por la autoridad central, por las razones que dimos en el numeral 1.7 de este artículo, referidas a la asistencia penal internacional pero perfectamente válidas para la extradición.

Creemos existe déficit a nivel de la normativa de fuente nacional, en el caso uruguaya, en lo atinente a la asistencia jurídica internacional en los delitos comunes, no en los de delincuencia organizada, en que existen como vimos las Leyes 17016, 17835, 18.494 y 17060, por no regular la misma el Código del Proceso Penal de 1980 ni el nuevo que regirá desde el $1^{\circ}$ de noviembre de 2017 . Ello genera problemas a la hora de tramitar pedidos de asistencia, tanto activos como pasivos, en ausencia de tratados, por lo que propusimos la solución analógica que indicamos en el numeral 1.13, in fine de este trabajo; mientras que en lo relativo a la extradición activa y pasiva, cuando no exista tratado vigente, el tema sí se reguló por el nuevo Código del Proceso Penal uruguayo, 
artículos 329 y ss., que entrará a regir el $1^{\circ}$ de noviembre de 2017.

\section{REFERENCIAS BIBLIOGRÁFICAS}

ÁlVAREZ COZZI, Carlos. (Ed.). Curso de Cooperación Penal Internacional. Valencia: Editor Carlos Álvarez, 1994.

ÁLVAREZ COZZI, Carlos. El arresto preventivo en los procesos de extradición. Montevideo: LJU T, 2004.

ÁLVAREZ COZZI, Carlos. Extradición, normas nacionales $y$ convencionales. $2^{\text {a }}$ ed. Montevideo: Editorial Universidad, 1997.

ÁLVAREZ COZZI, Carlos. La asistencia y la extradición en los delitos de narcotráfico y lavado de activos. Montevideo: Editores Asociados, 2001.

ÁLVAREZ COZZI, Carlos. La videoconferencia como medio probatorio en los procesos penales internacionales. Disponible en: <http:// pensamientopenal.com.ar/doctrina/38171-videoconferencia-medioprobatorio-procesos-penales-internacionales>

ÁLVAREZ COZZI, Carlos. Nuevo Código del Proceso Penal uruguayo y la asistencia penal internacional. Disponible en: $<$ http://pensamientopenal. com.ar/doctrina/44228-nuevo-codigo-del-proceso-penal-uruguayo-yasistencia-penal-internacional>

AMBOS, Kai. Cooperación y asistencia judicial con la corte penal internacional. Disponible en: <http://www.kas.de/wf/doc/kas_105841522-4-30.pdf?080602222526>

CERVINI, Raúl. Principios de cooperación judicial penal internacional en el protocolo del MERCOSUR. Disponible en: <http://wold.fder.edu. uy/contenido/penal/pdf/2010/cervini-004.pdf>

CONGRESO SUDAMERICANO DE DERECHO INTERNACIONAL PRIVADO. Tratado sobre derecho penal internacional. Montevideo, 23 de enero de 1889. Disponible en: <https://www.pj.gob.pe/wps/wcm/con nect/6fccc1804972a650ae78ffcc4f0b1cf5/Tratado+de+Derecho+Penal+ Internacional+de+Montevideo.pdf?MOD=AJPERES $>$

INSTITUTO SUPERIOR IBERO-AMERICANO DE ESTUDOS CRIMINAIS. Curso de Cooperación Penal Internacional. Montevideo: Carlos Alvarez Editor, 1994. MERCOSUR. Protocolo de San Luis de Asistencia Jurídica Mutua en Asuntos Penales entre los Estados parte del MERCOSUR, 1996. Disponible en: <https://legislativo.parlamento.gub. uy/temporales/6766534.HTML> 
NACIONES UNIDAS. Convención de las Naciones Unidas contra el Tráfico Ilícito de Estupefacientes y Sustancias Sicotrópicas. Viena, 20 de diciembre de 1988. Disponible en: <https://www.unodc.org/pdf/ convention_1988_es.pdf>

NACIONES UNIDAS. Convención de las Naciones Unidas contra la Delincuencia Organizada Transnacional. Palermo, Italia, 15 de noviembre de 2000. Disponible en: <https://www.unodc.org/pdf/cld/ TOCebook-s.pdf>

NACIONES UNIDAS. Convención Interamericana contra la Corrupción. Caracas, Venezuela, marzo 29 de 1996. Disponible en: <https://www. oas. org/juridico/spanish/firmas/b-58.html>

NACIONES UNIDAS. Convención Interamericana sobre Asistencia Mutua en Materia Penal. Nassau, Bahamas, 23 de mayo de 1992. Disponible en: $<$ http://www.oas.org/juridico/spanish/ tratados/a-55.html>

SANDOVAL MESA, Jaime Alberto. Instrumentos internacionales de cooperación judicial en materia penal, en la lucha contra los principales agentes de criminalidad en el derecho colombiano. Disponible en:<file://C:/Users/Admin/Documents/Dialnet-InstrumentosInternac ionalesDeCooperacionJudicialEn-3626830.pdf>

URUGUAY. PODER LEGISLATIVO. Ley No 17.016 del 7 de octubre de 1998. Normas referentes a estupefacientes y sustancias que determinen dependencia física o psíquica. Montevideo, Registro Nacional de Leyes y Decretos, 1998.

URUGUAY. PODER LEGISLATIVO. Ley No 17008 del 25 de setiembre de 1998. Aprueba la Convención Interamericana contra la Corrupción. Montevideo, Registro Nacional de Leyes y Decretos, 1998.

URUGUAY. PODER LEGISLATIVO. Ley No 17060 del 10 de diciembre de 1998. Normas referidas al uso indebido del poder público (corrupción). Montevideo, Registro Nacional de Leyes y Decretos, 1998.

URUGUAY. PODER LEGISLATIVO. Ley $N^{o} 17343$ del 23 de mayo de 2001. Relativa a estupefacientes y sustancias que determinen dependencia física o psíquica. Montevideo, Registro Nacional de Leyes y Decretos, 2001.

URUGUAY. PODER LEGISLATIVO. Ley No 17835 del 14 de septiembre de 2004. Sistema de prevención y control del lavado de activos y de la financiación del terrorismo. Montevideo, Registro Nacional de Leyes y Decretos, 2004.

URUGUAY. PODER LEGISLATIVO. Ley $N^{o} 18494$ del 5 de julio de 
2009. Control y prevención de lavados de activos. Disponible en: $<$ https:// parlamento.gub.uy/documentosyleyes/leyes/ley/18494>

VIEIRA, Manuel. Extradición. Montevideo: FCU, 2001.

\section{RESUMEN BIOGRÁFICO}

Carlos Álvarez Cozzi es Catedrático Grado 5, Titular de la Unidd Curricular de Derecho Privado, desde 2005 y Coordinador de la Unidad Académica Jurídica, desde 2012. Profesor de posgrado en la UPAE, FCEA, UdelaR. Profesor Adjunto de Derecho Internacional Privado, FD, UdelaR, 1993-2012. 